\title{
O NEM SEMPRE CONVENIENTE VERDE: ESTUDOS PRELIMINARES DE CONCEITUAÇÃO E TIPIFICAÇÃO DE FITOPATOLOGIAS URBANAS EM ESPAÇOS PÚBLICOS
}

\author{
THE NOT ALWAYS CONVENIENT GREEN: PRELIMINARY STUDIES ON \\ URBAN PHYTOPATHOLOGY CONCEPTION AND TYPIFICATION IN OPEN SPACES
}

\author{
Matheus Maramaldo Andrade Silva* \\ Flaviana Barreto Lira** \\ Glauco de Paula Cocozza***
}

\section{RESUMO}

Por meio da leitura da História percebe-se que as plantas têm ocupado importante papel na evolução do planeta e da vida - cada vez mais urbanizada. Como foco atual para a "sustentabilidade" têm se firmado como solução primeira de muitas problemáticas globais. Porém cabe perguntar: os elementos vegetais só trazem benefícios às urbes? $O$ incorreto plantio e 0 crescimento natural da vegetação também podem dispor prejuízos ao cotidiano, fato que se pode denominar de fitopatologias urbanas. A partir dessas variáveis, procurou-se neste trabalho esboçar esse conceito, criar tipos de análise e produzir uma ferramenta preliminar de identificação de problemas relacionados à vegetação urbana, levantando uma Superquadra de Brasília (DF, Brasil). Isso reafirmou a necessidade de bons projetos paisagísticos e a conscientização popular, além de ter disposto o esboço de mais uma ferramenta de prevenção e diagnóstico.

Palavras-chave: Fitopatologias urbanas. Paisagismo. Espaços livres. Vegetação.

\section{ABSTRACT}

By reading History, we recognize that plants occupy an important role in planet evolution and, by this reason, urbanized life growth and the actual focus for "sustainability", vegetation has been establishing itself as the first solution for many global problems. However, we should ask: Vegetation elements really bring only benefits to cities? The incorrect planting and sometimes the own natural growth of vegetation may also afford damage to the quotidian, a fact that can be called urban phytopathologys. Now, based in this variable, this paper seeks to sketch its concept, builds types of analysis and produces a primary tool of identification of these problems related with urban vegetation, studying one Super Quarter of Brasilia, Brazil. It reaffirmed the need of good landscape projects, the public awareness, as showed a sketch of another tool for prevention and diagnosis. Keywords: Urban phytopathologys. Landscape. Open spaces. Flora.

\footnotetext{
* Universidade de Uberlândia, Faculdade de Arquitetura e Urbanismo e Design. Avenida João Naves de Ávila, 2.121, CEP 38400-902, Santa Mônica, Uberlândia, MG CV: http://lattes.cnpq.br/1168026728043259 mmaramaldo@gmail.com

** Universidade Federal de Pernambuco, Faculdade de Arquitetura e Urbanismo Avenida Prof. Moraes Rêgo, 1.235, CEP 50670-901, Recife, Pernambuco, PE. CV: http://lattes.cnpq.br/5319666239065472 flavianalira@hostmail.com

*** Universidade de Uberlândia, Faculdade de Arquitetura e Urbanismo e Design. Avenida João Naves de Ávila, 2.121, CEP 38400-902, Santa Mônica, Uberlândia, MG. CV: http://lattes.cnpq.br/5848222126794015 glauco_cocozza@yahoo.com.br
} 


\section{INTRODUÇÃO}

Quando se fala de vegetação, é comum associá-la à natureza bucólica iluminista, embora não se possa expressar isso como uma verdade absoluta, pois nem todos gostam de árvores. Esse pensamento, muito presente na sociedade atual, pode ser interpretado como herança da razão rousseauniana e da projetação que sucedeu a Idade Média, principalmente a partir do século XVIII, quando a urbanização se desenvolveu rumo a uma realidade opressora (conforme essa linha de raciocínio) e se começou de fato a projetar com as plantas em função da melhoria das cidades (MACEDO, 1992; DOURADO, 2011). Segundo Fulgeri $(2003$, p. 6) [...] a civilização e a sociedade corrompem o homem, é necessário recorrer ao sentimento, voltar à natureza que é boa". Para Berque (1994, p. 18, tradução do autor): "O imaginário da paisagem arcádica tende a impor o espetáculo de imutável felicidade. Conforme Dourado (2011, p. 29, 31):

[...] havia uma mentalidade que considerava a difusão dos jardins públicos capaz de civilizar a massa de trabalhadores [...] $\bigcirc$ reconhecimento das árvores como um recurso a serviço da salubridade urbana também foi um motivo que pesou para que [...] levasse adiante [...] (DOURADO, 2011, p. 29, 31).

Partilhando dessa interpretação filosófica e social, continua-se evoluindo, agregando em cada nova teoria e no desenvolvimento das artes e ciências mais valores à imagem que se tem da vegetação. Noções estéticas, informações medicinais e nutricionais comprovadas, um boom em torno da 'sustentabilidade' e da ecologia, tudo isso incluiu de vez o verde na mente das pessoas junto com os sistemas econômico, alimentar e de paisagem panorâmica extraurbana com pontos positivos (MASCARÓ, J.; MASCARÓ, L., 2015):

A ideia de arborização urbana vem, portanto, passando ao longo do tempo por uma evolução. De uma abordagem inicial voltada apenas para o aspecto estético e de estrutura formal entre árvore e paisagem, foram incorporados outros enfoques que consideram também os benefícios psicológicos e os valores e significados simbólicos [...] (FARAH, 2004, p. 102).

Nas cidades, seguindo o descrito por Dourado (2009), as plantas são esboçadas como elementos fundamentais para a melhora da vida urbana, e isso é constantemente reforçado por ecologistas, biólogos e paisagistas, que descrevem inúmeros aspectos benéficos da vegetação:

As plantas nos dão conforto nas mais diversas formas [...] As árvores nos proporcionam sombra, barram os ventos fortes, limpam o ar polvído, amenizam as temperaturas e enquadram vistas [...] podem ser usadas para proteger o solo da erosão, absorver o excesso de água que escoa durante as tempestades ou retirar contaminantes do solo 
poluído, entre tantos outros atributos positivos (WATERMAN, 2009, p. 75).

O que se percebe em leituras variadas é a tendência de o verde ser uma solução geral para muitos dos problemas urbanos, principalmente ambientais e estéticos. São necessários mais parques servindo de pulmões para as cidades, calçadas mais bem sombreadas ou criar mais embates entre o concreto e o natural, tornando as visuais mais coloridas, por exemplo, o que as árvores, consorciadas com os outros estratos (arbustos, herbáceas, forrações e palmeiras), possibilitam (figura 1). $\bigcirc$ verde acaba por revelar-se uma necessidade.

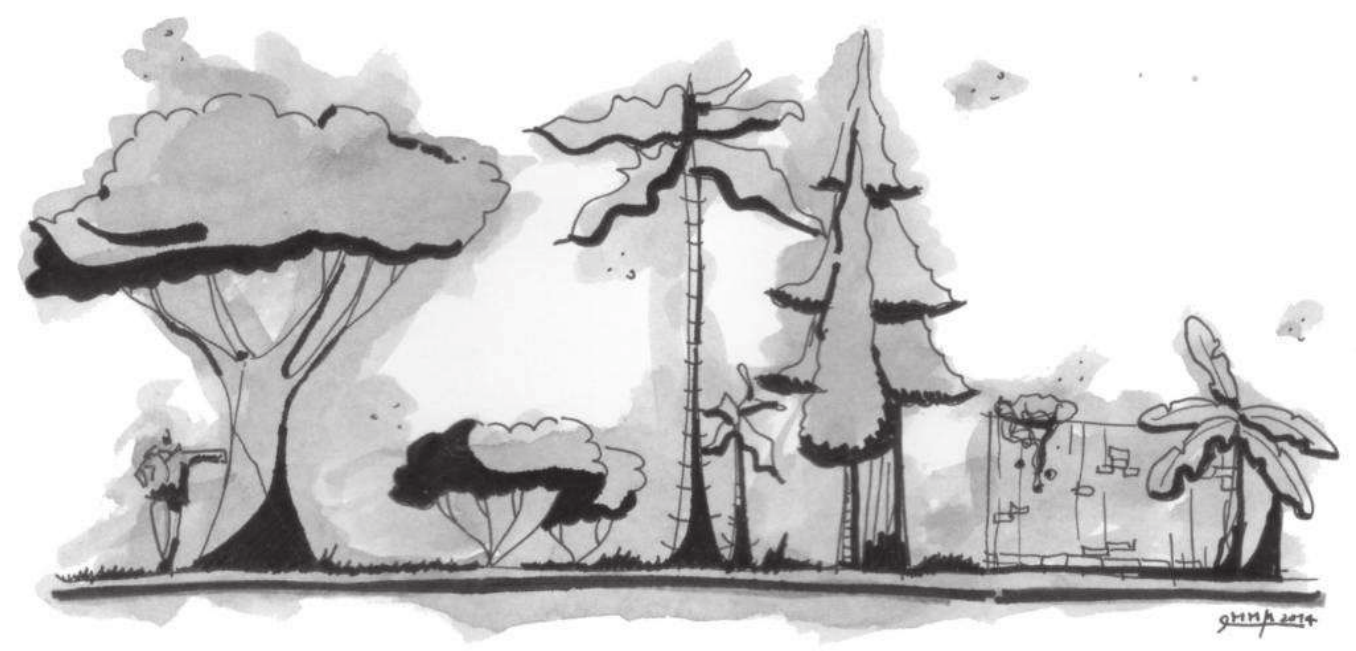

Figura 1 Croqui com os estratos variados das plantas. Autor: Matheus Maramaldo, 2014.

Também cabe discutir como estamos inserindo a vegetação nas cidades e quais são os ocasos desse processo, principalmente nos espaços livres públicos. Toda e qualquer intervenção vegetal é $100 \%$ benéfica ao meio urbano, como normalmente se imagina? Olhando minuciosamente para os percursos diariamente transcorridos, notase que não, ou pelo menos não totalmente: o translado vegetado nem sempre é tão agradável; há relevos ocasionados por raízes, chegando por vezes a gerar percepção de perigo a partir de matagais e sombras. Quando não há um projeto qualificado, ou mínimos cuidados de implantação e manutenção, o natural pode ameaçar a saúde, a segurança e até mesmo a cadeia social das cidades. Espaços vegetados são produzidos muitas vezes sem levar em consideração a dinâmica real da vegetação, o que pode ser bastante adverso, mesmo sendo necessária sua presença.

Sabendo da extensa galeria de trabalhos acerca do objeto 'vegetação urbana', e como esta colabora no sentido de qualificação das urbes, percebeu-se a existência de uma brecha pouco discutida: a existência de problemas nos espaços livres das cidades ocasionada pela má implantação vegetal. Este texto continuará explorando tal objeto no sentido de avaliar certos processos que também ocorrem quando plantamos, os 
aspectos insatisfatórios, buscando agregar à literatura mais bases de questionamento sobre a nossa produção espacial, como um exercício de prudência. Em que medida o verde se torna problemático à paisagem urbana? $\bigcirc$ que é problemático, por que é problemático e como se pode desmontar esses problemas?

Essa discussão foi construída a partir de revisão da literatura, definição do tipo de área de estudo e elaboração de tipologias de análise, culminando num levantamento campal com fichamento diagnóstico, tendo como recorte espacial um espaço livre público planejado - uma Superquadra de Brasília (DF, Brasil) - para exemplificar que até mesmo em áreas ditas 'qualificadas' é possível enxergar problemas relacionados ao verde. Espera-se que este estudo e a ferramenta por ele proposta sirvam de reflexão sobre como se está atuando na paisagem urbana, que possam contribuir com novas tomadas de decisão projetuais e de intervenção e diminuir os erros acompanhados pelos empirismos de plantio.

\section{VEGETAÇÃO E CIDADE (O ESPERADO)}

Apesar de a vegetação ter a singela descrição "conjunto de plantas que povoam uma área determinada", no dicionário Michaelis, apresenta-se de forma muito mais ampla quando se avança além da etimologia da palavra. As plantas são epidêmicas, com diversas cores, formas, tamanhos, e encantam as pessoas com suas combinações variadas não inertes (FARAH, 2004; MASCARÓ, J., MASCARÓ L., 2015). Hoje não são mais tratadas como meros exemplares do quintal, estando no centro de quase todas as discussões, principalmente acerca da 'sustentabilidade'. Ao estudá-las, é possível utilizar várias óticas, como a botânica ou a paisagística, que revelarão variantes da evolução, da taxonomia, do habitat, dos estratos, entre outras características.

Quando se agrega o qualitativo urbano à vegetação, não somente se fala das plantas habitando as cidades, como se exercita um novo olhar e uma nova relação entre os seres humanos e tais elementos (FARAH, 2004; LAMAS, 2014). A paisagem urbana, que se desenvolve permeada também por árvores, arbustos e forrações, evolui com linguagens totalmente diferentes a partir da entrada desses componentes (figura 2): uma rua com prédios altos tem uma profusão visual $x$ e possivelmente menor acolhimento dos usuários, que podem se sentir diminutos diante de espaço tão vertical; a mesma rua, dotada de árvores em sequência regular, já transita para uma profusão visual $x / 2$ ou menos e certamente os transeuntes se sentem melhor com teto mais baixo e espacialidade virtualmente menos antrópica - as copas regularizam as perspectivas e amenizam temperaturas. São combinações e situações que tornam a vegetação nas cidades peça importante, que modifica a paisagem - não como na natureza pura, mas como elemento de hierarquia semelhante aos ditos "ingredientes tectônicos" (fachadas, passeios etc.) (LAMAS, 2014; MASCARÓ, J.; MASCARÓ, L., 2015).

Do canteiro à árvore, ao jardim de bairro ou ao grande parque urbano, as estruturas 
O Nem Sempre Conveniente Verde: Estudos Preliminares de Conceituação e Tipificação de Fitopatologias Urbanas em Espaços Públicos

verdes constituem também elementos identificáveis na estrutura urbana. Caracterizam a imagem da cidade; têm individualidade própria; desempenham funções precisas; são elementos de composição e do desenho urbano; servem para organizar, definir e conter espaços. Certamente que a estrutura verde não tem a mesma "dureza" ou permanência que as partes edificadas da cidade. Mas situa-se ao mesmo nível da hierarquia morfológica e visual. [...] Um traçado pode ser definido tanto por um alinhamento de árvores como por um alinhamento de edifícios (LAMAS, 2014, p. 106).

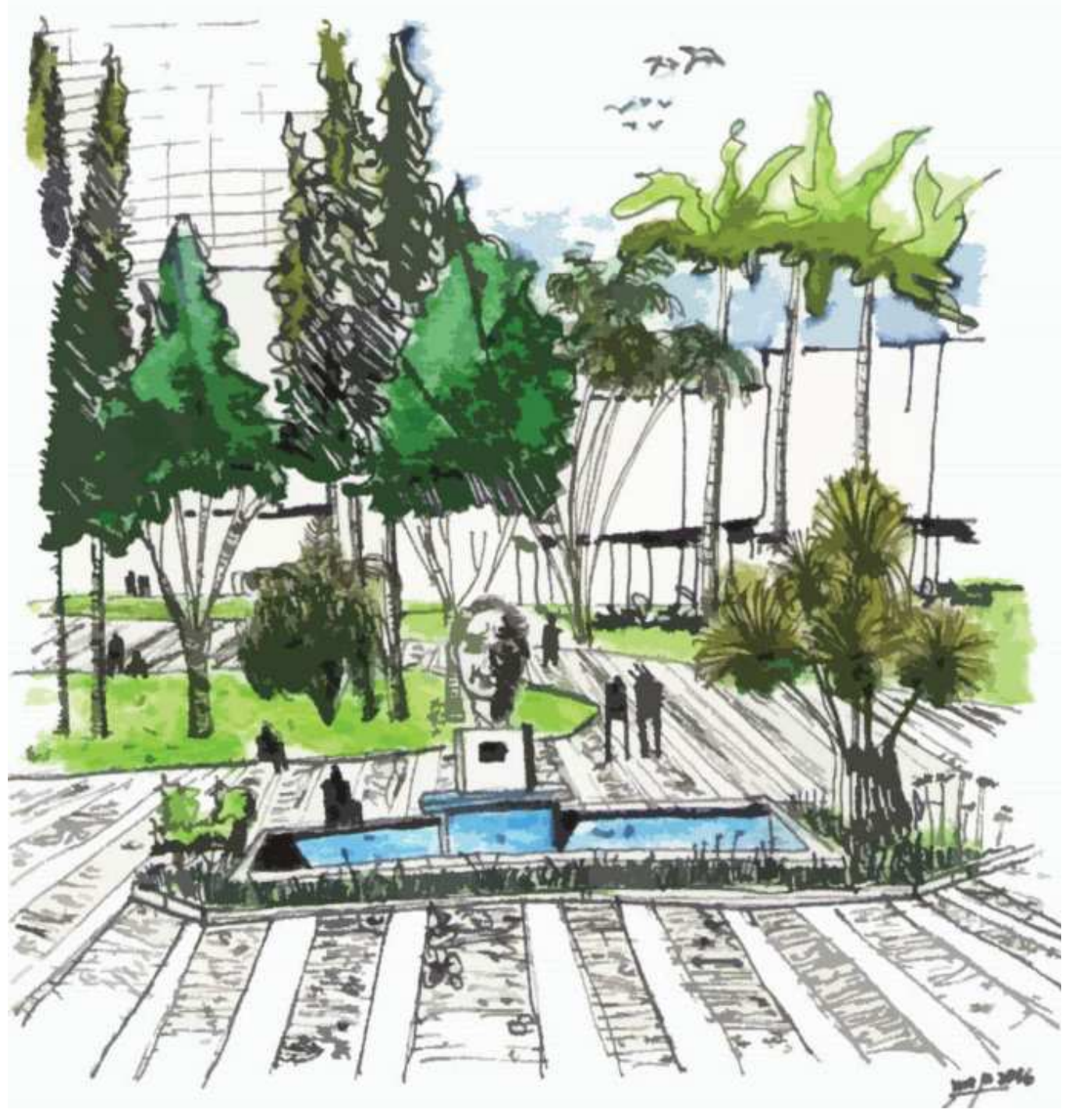

Figura 2 Croqui mostrando a construção da vegetação no espaço. Praça Tubal Vilela, Uberlândia, MG. Autor: Matheus Maramaldo, 2016.

Assim, nas nossas cidades, trata-se de elemento compositivo de muitos espaços livres, distribuído em espaços verdes e vegetados, privados e públicos, cujos usos implicarão percepções e questões diferenciadas (MACEDO, 1995). Mais especificamente nos livres 
e públicos, como ruas, praças e parques, as plantas orquestram relações fortemente interativas com o contexto geral urbano, não se restringindo a lotes, demonstrando dinâmicas que afetam todos os usuários, moldando a forma urbana e a qualidade da caminhabilidade, criando jogos de sombras, pontos focais e marcos, coberturas e direcionamentos'. Nesses espaços, de fato, a vegetação urbana pode recriar a vocação espacial, produzindo ambientes que funcionam como barreiras ecológicas, ou permitindo a livre circulação e o estar com extensões gramadas, avançando dos aspectos ambientais para outros, contemplativos e de lazer (MALAMUT, 2014):

A presença da vegetação, dependendo de seu porte em relação à edificação, pode criar planos que organizem e dominem o espaço urbano através da unificação, ou simplesmente formar uma cobertura vegetal aconchegante para quem passa por baixo de suas copas sem modificar o perfil da edificação [...] ajudam a minimizar o aspecto edificado da paisagem (MASCARÓ, J.; MASCARÓ, L., 2015, p. 32-33).

Trata-se de recorrente esforço de desantropização paisagística no qual o verde é fundamental.

\section{VEGETAÇÃO E CIDADE² (FITOPATOLOGIAS)}

Apesar da mística e da extensão da literatura contida nos manuais acerca das necessidades de profusão do verde nas cidades, com a obviedade das qualidades que a vegetação agrega ao urbano, o que se vê como realidade é uma produção espacial que muitas vezes desperdiça as reais potencialidades das plantas. Mais: omite riscos e traz gravidade ao contexto das cidades, comumente sem a anvência dos próprios difusores - os planejadores e a população (SILVA, 2014; MASCARÓ, J.; MASCARÓ, L., 2015).

As plantas, embora não pareçam, são exigentes e nas urbes cobram os mesmos direitos que na natureza - melhor espaçamento entre os indivíduos, quantidade ideal de luz, fartura de nutrientes e facilidades para reprodução (SALVIATI, 1993). Nessa busca ininterrupta por vida, com ou sem ação antrópica, criam-se contextos pouco cogitados (até mesmo pelos manuais) aos quais se deveria prestar mais atenção: são eles os problemas fitopatológicos urbanos. Mas o que viria a ser isso?

Uma definição resumida diria que fitopatologias urbanas são todas as problemáticas nocivas que se apresentam na cidade e que tenham a vegetação como fator-fim ou fator-meio de causa. Para exemplificar: após sair do carro, um usuário sobe uma calçada e começa a caminhar; em pouco tempo ele se depara com um desnível rachado no piso, do qual logo se nota a origem: as raízes de uma árvore próxima. Eventos como esse são justamente o que se quer descrever aqui.

\footnotetext{
1 Claro, muitos outros processos que extrapolam o visual, despertando todos os sentidos e alterando as esferas psicológica, física e ambiental (MALAMUT, 2014).

2 A anáfora é proposital.
} 
Gravidades como essa podem acompanhar diversos tipos de implantação vegetal nos meios urbanos, traduzindo-se em perturbações paisagísticas culturais, de desconforto ou de riscos (potenciais, com data marcada e/ou inerentes), por exemplo (figura 3). Para maior entendimento, foram tipificados tais ocasos ${ }^{3}$ com raciocínio conjunto de análise espacial ${ }^{4}$, verde urbano e morfologia vegetal ${ }^{5}$, estruturando três grandes grupos fitopatológicos nas cidades: ambientais-sanitários, físicos e psicossociológicos, cada um com particularidades e graus de afetação.

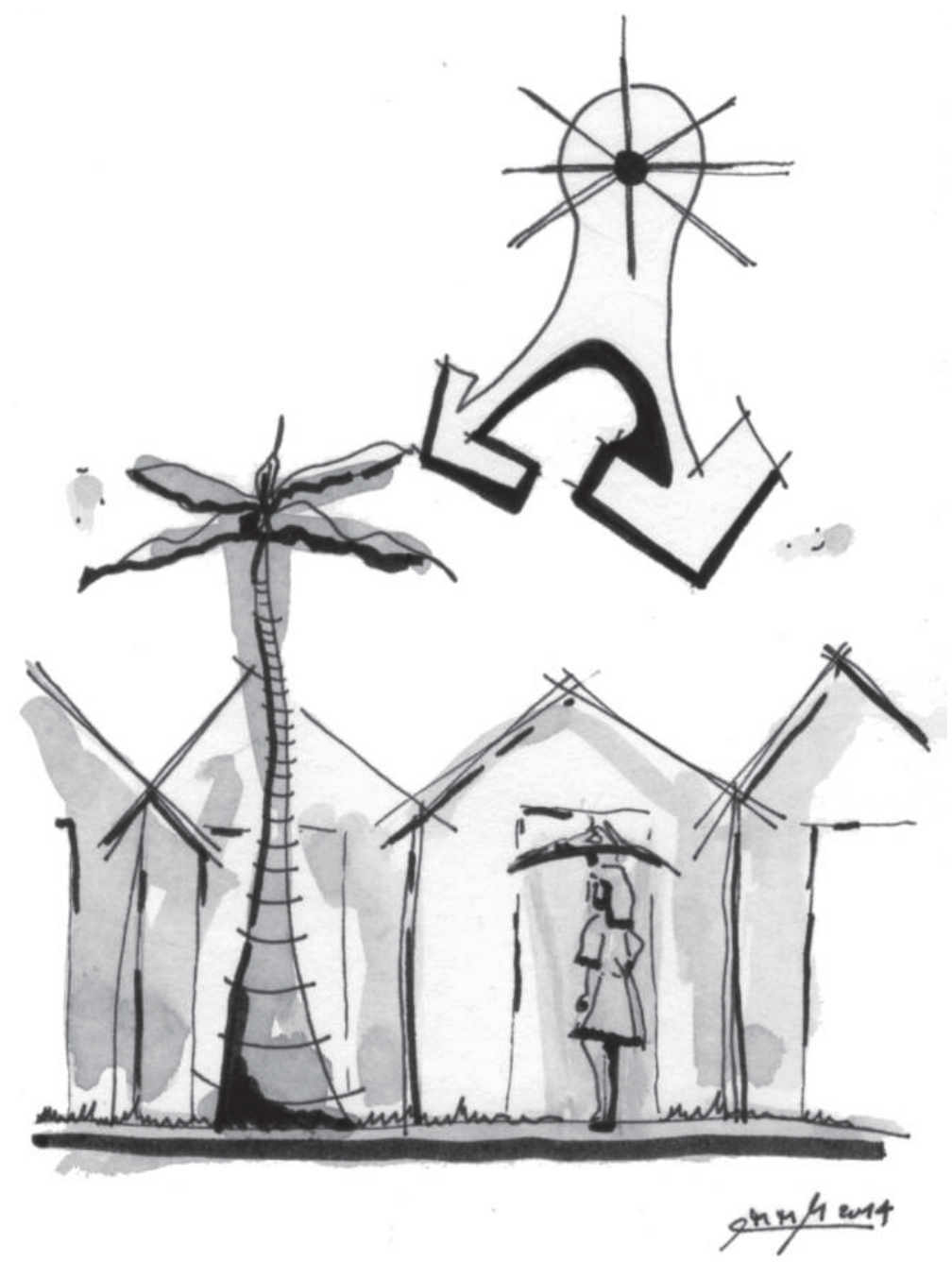

Figura 3 Croqui com exemplo de implantação de viés somente estético, expondo os usuários ao sol intenso.

Autor: Matheus Maramaldo, 2014.

3 Seguindo o processo metodológico de análise urbana de Panerai (2006), tipológico, e adaptando ao objeto estudado, vegetação urbana, tendo bastantes referências em NORIE / UFRGS (2003) e Mascaró, J. e Mascaró, L. (2015) para realizar esta interface.

4 Jacobs (2010); Kohlsdorf (1996); Lamas (2014), Lynch (2005), Malamut (2014), Sandeville Junior (2004).

5 AMMA (2008), Basso e Côrrea (2014), CEMIG (2011), Lima (2009), Gonçalves e Lorenzi (201 1), Mascaró, J. e Mascaró, L. (2015), Salviati, (1993), SMVMA (20-?). 
Quanto ao primeiro grupo, embora seja aconselhável ter plantas em espaços livres, com o intuito de sombreamento, ornamentação e diminuição dos corpos de concreto e asfalto, as intervenções vegetais impostas à cidade também podem ocasionar problemáticas ambientais e sanitárias durante o processo. Esses problemas, que aparecem parelhos a muitos plantios, estão relacionados ao conforto ambiental, intoxicações e sanidade vegetal, o qual o desconhecimento e uso incorreto dispõem de contratempos que, caso negligenciados, comprometem o cotidiano e aumentam a mortalidade nas urbes (MASCARÓ, J.; MASCARÓ, L., 2015).

Conexas aos aspectos de conforto, as características das plantas interferem diretamente na qualidade ambiental. Uma mesma árvore de copa densa e média altura pode ser ótima numa cidade quente, ensolarada e seca, assim como pode aumentar o fluxo de vento e escurecer a área numa cidade fria, nublada e úmida (SILVA, 2009; ROMERO, 2013; MASCARÓ, J.; MASCARÓ, L., 2015). O que é certo? Tratando das toxidades, a falta de cuidado na escolha das paletas expõe os usuários a plantas com conteúdo venenoso, entorpecente, alergênico, urticante ou corrosivo. Até elementos extremamente ornamentais podem ser altamente deletérios ${ }^{6}$ (LINK, 1988 apud MASCARÓ, J.; MASCARÓ, L., 2015, p. 113).

A fauna também permeia a caracterização da fitopatologia no momento em que certas plantas acabam por servir de abrigo e alimento para animais peçonhentos ou transmissores de doenças; algumas são especializadas na atração desses tipos zoológicos (RAVEN; EVERT; EICHHORN, 1992). Outras vezes há situações de trânsito entre as próprias espécies vegetais usadas, relações tróficas competitivas nas quais as plantas podem comprometer toda uma cadeia, parasitando ou inibindo o crescimento de outras, matando jardins e causando graves acidentes com a morte das hospedeiras (RAVEN; EVERT; EICHHORN, 1992). São levados em conta esses qualitativos no transcurso de plantios ${ }^{7}$ ?

Outros imbróglios - com características ainda mais empíricas - são os de origem física, relacionados à matéria. Podendo atingir de forma direta (deterioração física de matéria ocasionada diretamente pelo crescimento da vegetação) ou de forma indireta (elevação dos riscos de incidentes), as fitopatologias físicas afetam as infraestruturas urbanas tátil e/ou visualmente (SILVA, 2014). Numa rua a paisagem formada pela arborização pode, ao mesmo tempo, trazer referências oníricas e agradáveis, com as floradas no sentido ótico, assim como presenteá-la com o hesitante pêndulo da caída dos frutos pesados, que acabam por fulminar transeuntes e automóveis.

No plano do piso, observa-se destacamentos de material por ervas daninhas ou raízes superficiais e bases caulinares de árvores, por exemplo (AMMA, 2008). Em alturas maiores, galhadas e folhas podem prejudicar as estruturas ou quebrar outros elementos (CEMIG, 2011; SMVMA, s/d) (figura 4). Em deslocamento ágil, frutos, ou

\footnotetext{
6 Às vezes as pessoas são expostas a crenças e superstições simbolizadas por certas plantas. Não sabendo se é certo ou errado, algumas espécies são muito venenosas, mas têm um propósito de estarem ali.

7 A mesma árvore pode não ocasionar nenhum risco quando está no meio de um jardim, mas insiste-se em apresentá-la rente a calçadas.
} 
até a planta inteira, estão propensos a caírem, podendo causar acidentes (AMMA, 2008; SMVMA, s/d). A insistência na utilização de elementos cortantes nas cidades, figurados nos espinhos, acúleos e folhas navalhadas de certas plantas demonstram formas de agressão na busca obsessiva por segurança e afastamento (ou desconhecimento) (MASCARÓ, J.; MASCARÓ, L., 2015).

Um planejamento ineficaz ou a espontaneidade do crescimento do verde também potencializam acidentes, visto o encobrimento das sinalizações, postes, visuais e janelas (MASCARÓ, J.; MASCARÓ, L., 2015). Certos eventos nem partem da lógica da vegetação, de terceiros (pragas e eventos naturais), trazendo prejuízos sérios à cidade, principalmente materiais (danificando edificações e automóveis, por exemplo) (MASCARÓ, J.; MASCARÓ, L., 2015). Guapuruvus se mostram os mais belos semblantes das áreas em que estão, mas, ao lado das edificações, instigam o alerta de que uma ventania pode desvanecer tudo. Assim, as escolhas tornam a cidade um quebra-cabeças de fantasias estéticas e diálogos com a realidade da natureza, que morre, nasce e se transforma - inevitavelmente.

Entre os grupos levantados não podemos desconsiderar o terceiro, o que menos permeia o pensamento dos técnicos ${ }^{8}$, mas o que mais influencia as pessoas e as conexões nas urbes (FARAH, 2004) - o campo psicossociológico. Essa área está relacionada às percepções/sensações das pessoas em referência aos espaços e ciclos de atividades da cidade, associadas à multidisciplinar vegetação. Há um estreitamento entre a inteligibilidade espacial e as perturbações que certos elementos vegetais podem provocar a depender da implantação.

Apesar de normalmente existir a sensação de acolhimento pelas flores e do semblante suave que os estratos variados têm, a vegetação também está propensa a potencializar sensações avessas ao que usualmente se espera. Assim como os muramentos de alvenaria, cerceia-se a coletividade com 'tapumes verdes' - tornando as ruas habitats cegos, com sensação desconfortante de imprevisibilidade - ou afasta-se os usuários do caminho mais lógico ao criar tais barramentos (KOHLSDORF, 1996; TELES, 2005; JACOBS, 2010) (figura 5). De que adianta tanto verde se a sustentabilidade não penetra os seios da sociabilidade? $\bigcirc$ excesso não planejado, como a falta de trabalho paisagístico de áreas verdes, produz espaços também imprevisíveis, escuros, que a luz não penetra (MASCARÓ, L., MASCARÓ, L., 2015). Novamente, de que adianta ter 'pulmões' nas cidades se eles ocupam o lugar do 'coração' (a conectividade entre os bairros)?

Outra impressão frente a certos ambientes vegetados é a de hostilidade, que avança do simples emparedamento para um nível de agressão - os espinheiros denotam, não conotam, o afastamento. A inatividade provocada pelo desejo das extensões inacessíveis gramadas é outra forma de dissolver o potencial de usos e atividades em tais áreas para prover uma contemplação ineficaz de exigente manutenção (TELES, 2005).

8 Normalmente não arquitetos, em resposta a soluções de infraestrutura urbana - não à paisagem como um todo. 


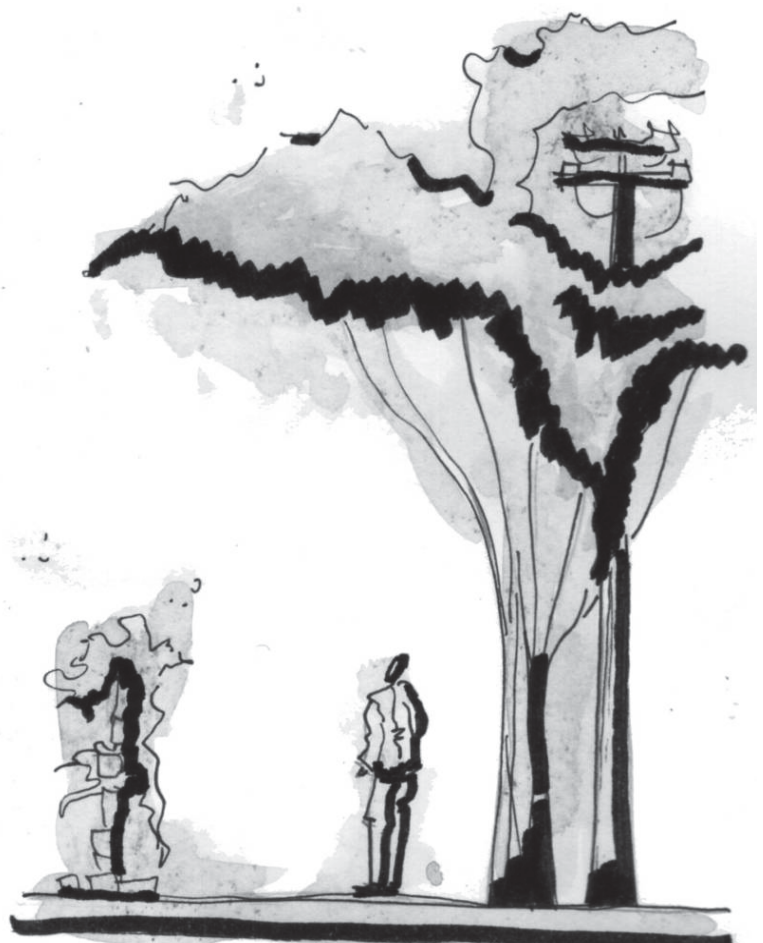

enmpheme

Figura 4 Croqui das interferências em altura. Onde está o poste?

Autor: Matheus Maramaldo, 2014.

Figura 5 Croqui do cercamento vivo como paliativo aos muros de concreto. Mas é o único caminho?

Autor: Matheus Maramaldo, 2014. 
Há também situações em que a inteligibilidade espacial difere das qualidades sociais e entra com maior intensidade no campo percepcional e topoceptivo. Uma linguagem com espécies pouco variadas pode ser monótona. Criar labirintos semelhantes às quadrículas urbanas sem marcos ou a existência de elementos vegetais isolados e de pouca expressão somente reforçam a configuração de apêndice daquele objeto no espaço (KOHLSDORF, 1996; LYNCH, 2005). A produção espacial tem se pautado em trazer as qualidades ambientais da vegetação para a cidade, mas não prevendo os impactos sociais nos quais esta pode incorrer, como uma linguagem propositiva (não passiva).

\section{METODOLOGIA DE ANÁLISE}

Conhecendo essa abrangência de possibilidades fitopatológicas, cabe pensar na problemática introduzida no começo deste texto, no qual talvez não se deveria achar que o verde é bom pelo simples fato de ser verde. Partindo desse princípio, qual ferramenta metodológica se prestaria a analisar os impactos negativos do mau planejamento da vegetação na urbe?

Considerando as reduzidas referências obtidas sobre o tema, adotou-se como recurso metodológico a analogia de textos de análise urbana e paisagística (PANERAI, 2006; SANDEVILLE JUNIOR, 2004) com outros, de vegetação urbana (FEDRIZZI; TOMASINI; CARDOSO, 2003; MASCARÓ, J.; MASCARÓ, L., 2015), e graficação de danos (TINOCO, 2009). A partir dessas leituras, foram traçados os pontos fundamentais do processo, principalmente da divisão de etapas e do olhar que se deveria ter perante o problema. As etapas são:

- Definição de tipo de área de estudo e do local propriamente: espaços livres ou fechados? Espaços públicos ou privados? Qualquer espaço livre ou um tipo em especial (rua, praça, quadra etc.). Neste trabalho, preferiu-se abordar o espaço livre público Superquadra;

- Tipologias a serem analisadas: fitopatologias ambiental-sanitárias, físicas e psicossociológicas (pode-se optar por um só parâmetro, mas aqui optou-se pelos três);

- Levantamento campal: pontuar em mapas e tabelas a vegetação existente em todos os seus estratos (ou não), os elementos construídos e fluxos e o que cada um desses elementos vegetais influencia - de modo positivo e negativo (caso ocorra);

- Resultados e análise: apresentar tais estudos de forma parametrizada (textos, mapas, fotos, gráficos e/ou tabelas) e discuti-los - pode-se pensar nas origens, no que implica a existência dos mesmos, o que é de fato importante para ser revisto, pontuar o que é positivo e rascunhar alternativas.

\footnotetext{
9 Para a identificação botânica teve-se o auxílio de Gonçalves e Lorenzi (2011) e Souza e Lorenzi (2012). 
O exercício foi feito na Superquadra 308 Sul do Plano Piloto de Brasília (DF, Brasil). Escolheu-se tal local devido à quantidade de vegetação existente e à qualidade atrelada ao projeto paisagístico de Burle Marx. Será que a presença de um paisagismo tornou esse espaço livre público um ambiente de plena satisfação relacionada à vegetação? As interferências humanas posteriores provocaram o quê?

\section{RESULTADOS E DISCUSSÃO}

A partir da definição das etapas acima, realizou-se o estudo no recorte físicoespacial definido - árvore por árvore, arbusto por arbusto, interpretando as sensações em cada ambiente e as relações que se estabelecem entre o usuário e o verde. Foram anotadas as impressões e os fatos explícitos que se buscavam no espaço e nas plantas.

A Superquadra SQS 308 do Plano Piloto de Brasília, inaugurada em 1962, representa os conceitos fundamentais da cidade, trazendo uma espacialidade modernista em que o solo é quase por completo público e livre, as ruas são transfiguradas em vias de acesso coligadas às estruturas dos pilotis, as edificações seguem uma ordem definida pelo plano maior da cidade e quase tudo é permeado pelas áreas verdes (mapa 1). Os prédios com seis pavimentos, que pousam suaves no chão, são partes de uma das primeiras quadras construídas em Brasília, contando com o paisagismo de Roberto Burle Marx (mapa 2). Esse espaço, projetado a partir da lógica dos anos 1960, possui quantidade de vegetação elevada (mapa 3), principalmente árvores e arbustos bem desenvolvidos, criando um ambiente de tetos elevados - as perspectivas associadas à cidade, de visualização livre do céu, perdem-se nas visuais das folhagens em grande parte do lugar (difícil saber se há prejuízo). Há um sentido formal similarmente forte, visto a arquitetura paisagística, onde os pisos e os plantios seguem um ordenamento visualmente notável.

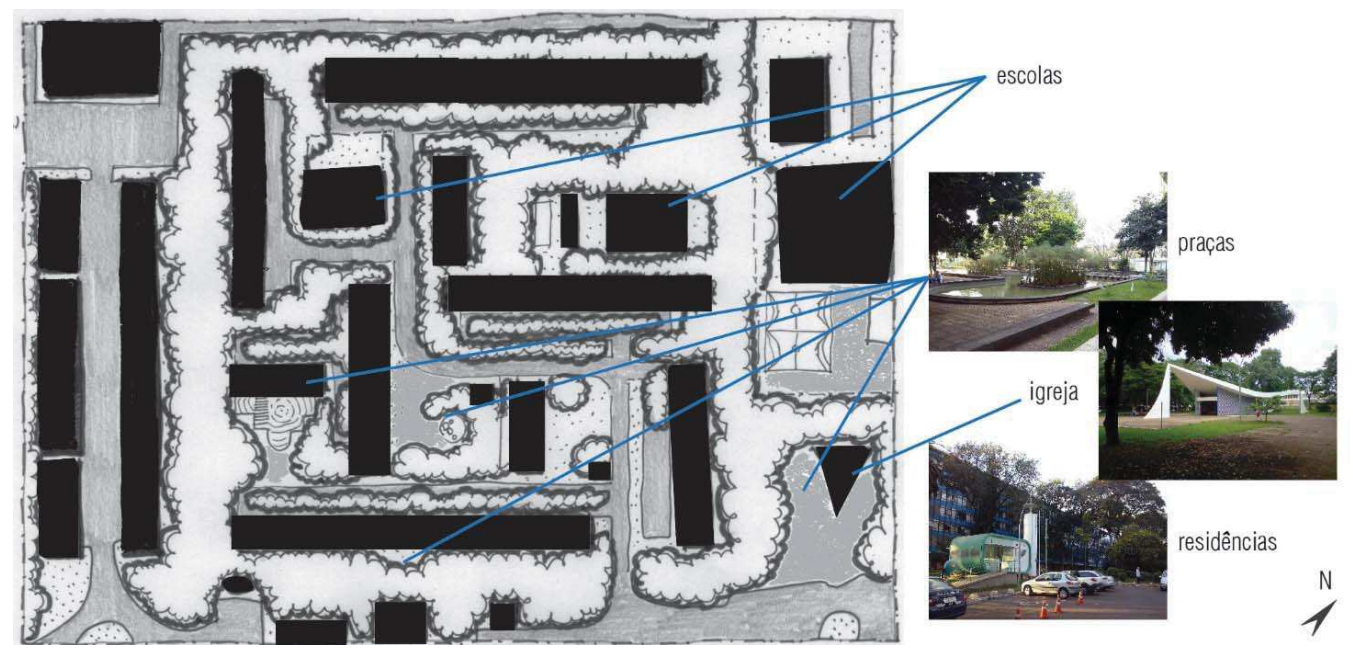

Mapa 1 Mapa de situação, SQS 308, revelando edificações em pilotis, outros equipamentos, vegetação e ruas. Um espaço bastante permeável e típico da cidade. Escala 1:4000.

Fonte: Imagens e Mapa de base SICAD-GDF produzidos por Matheus Maramaldo, 2014. 


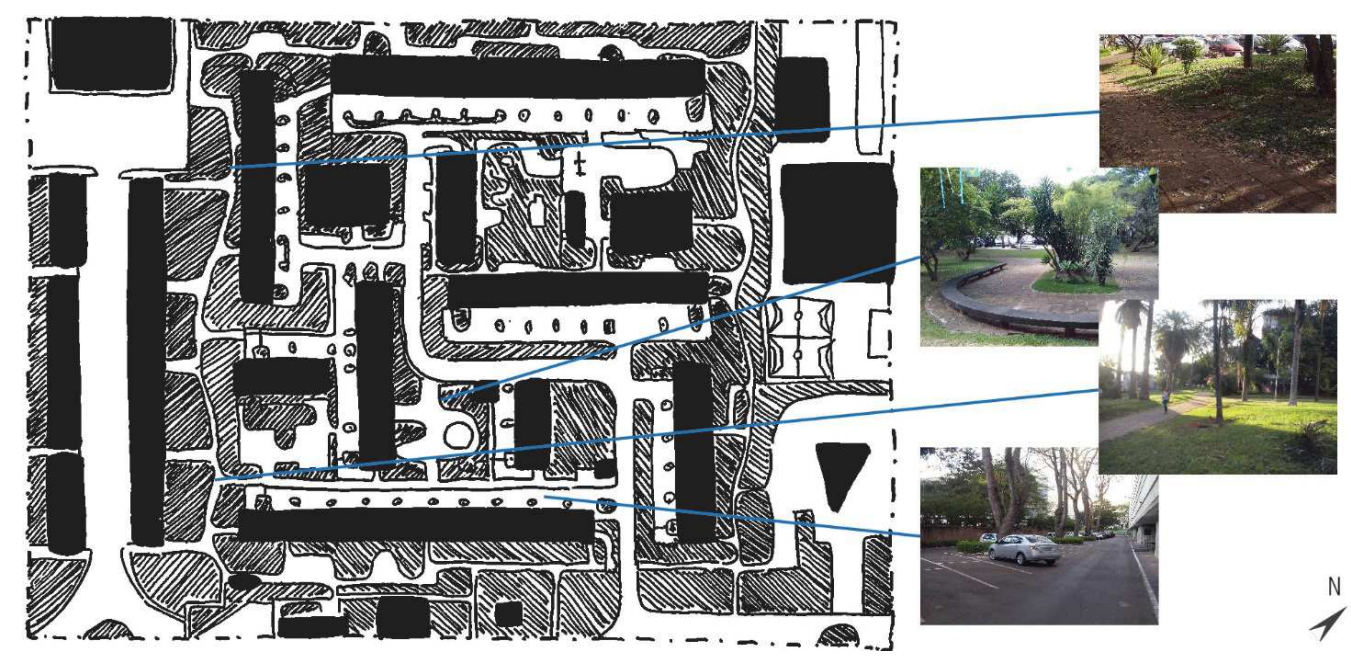

Mapa 2 Mapa de pisos, SQS 308, demonstrando passeios e desenho paisagístico de Burle Marx. Os hachurados mostram as áreas gramadas; pintados por completo, as edificações - que em sua maioria têm livre trânsito. Escala $1: 4000$.

Fonte: Imagens e Mapa de base SICAD-GDF produzidos por Matheus Maramaldo, 2014.

Contudo, percebe-se que as intervenções posteriores, certas escolhas de espécies e a idade avançada das plantas - mais de cinquenta anos - já trouxeram problemas ao local do estudo de caso (mapa 4). Há muitas plantas tóxicas próximo dos usuários (coroas-de-cristo, jasmins-manga, aráceas e poinsétias), outras com espinhos e folhas cortantes pouco protegidas (coroas-de-cristo, primaveras, agaves, palmeiras), paineiras e abacateiros em zonas de circulação com frutos podendo cair em carros e pessoas de alturas vertiginosas - como as próprias plantas em si, visto a fragilidade que a idade revela - ou o destacamento do piso após a pulsão de raízes e troncos pela estabilidade e nutrientes das plantas (paineiras, figueiras).

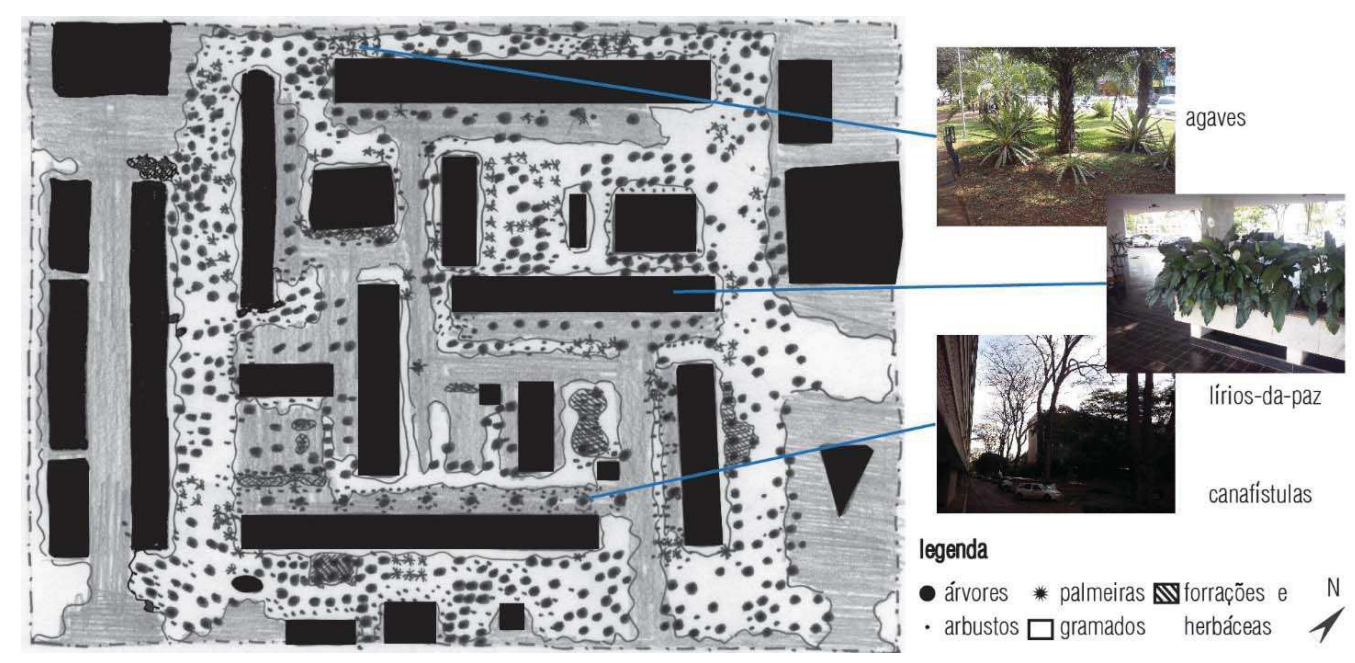

Mapa 3 Mapa de vegetação, SQS 308, contendo principalmente árvores e arbustos que se espalham homogeneamente pela quadra. Escala 1:4000.

Fonte: Imagens e Mapa de base SICAD-GDF produzidos por Matheus Maramaldo, 2014. 


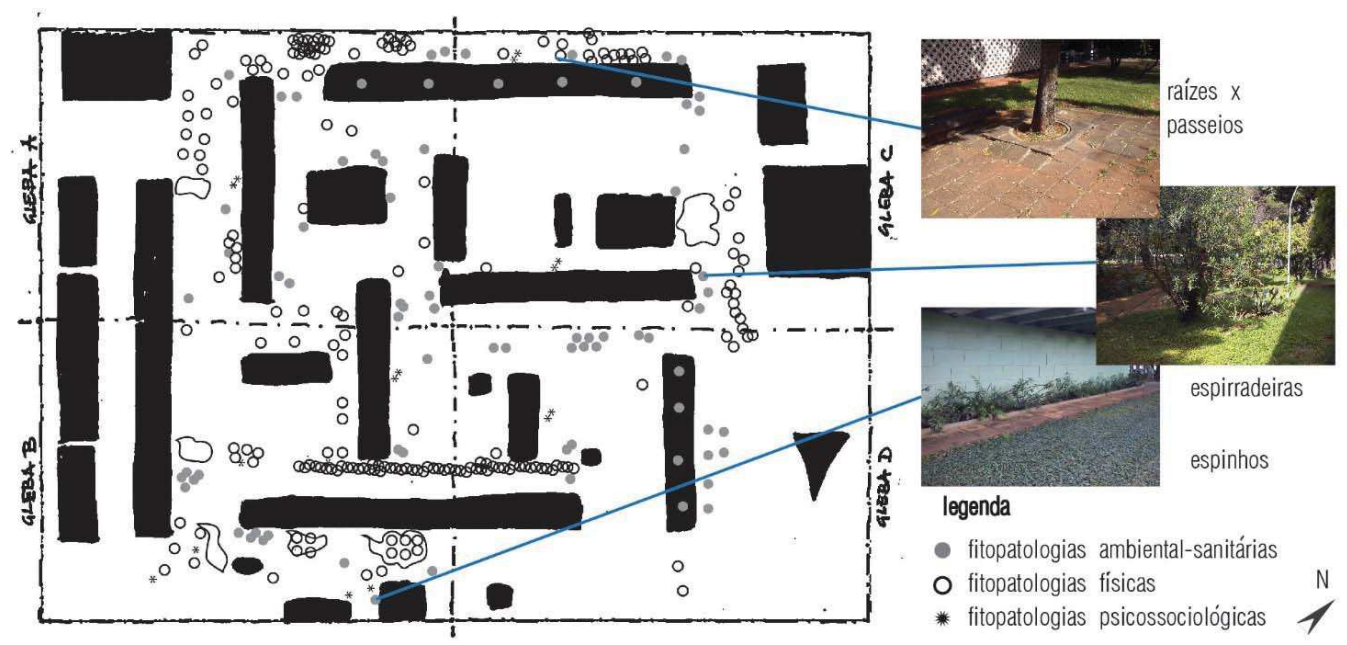

Mapa 4 Mapa de fitopatologias, SQS 308, dividido em quatro glebas. Notam-se problemas relacionados à vegetação principalmente nas bordas - teoricamente menos projetadas - e grande profusão de problemáticas físicas. Escala 1:4000.

Fonte: Imagens e Mapa de base SICAD-GDF produzidos por Matheus Maramaldo, 2014.

As plantas mais altas já apresentam sinais de idade avançada, o que nem sempre é positivo em meio urbano. Foram encontradas 288 ocorrências dos três tipos de fitopatologias urbanas, com destaque para os problemas de origem física (ver gráfico).

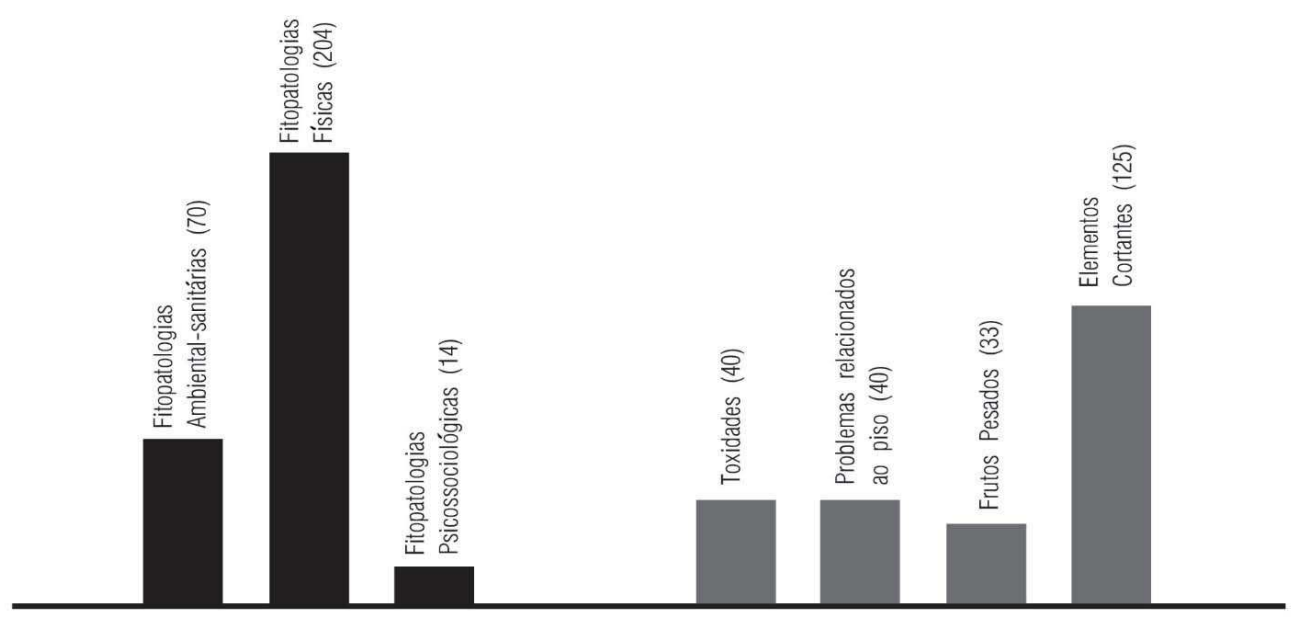

Gráfico demonstrando as quantidades aferidas de fitopatologias urbanas na quadra (preto) e as principais ocorrências (cinza). Fonte: Produzido por Matheus Maramaldo, 2016.

Entende-se que as problemáticas graves, como plantas tóxicas e cortantes próximo dos passeios e desprotegidas, devem ser revistas, preferencialmente eliminadas. A reposição paulatina da arborização visando à prevenção também deveria ser pensada. Não sabendo ao certo o que é elevado e o que é um número baixo, fica a impressão que os ocasos vistos são diminutos perto dos benefícios da vegetação incorporados pela população e pela paisagem. Embora criando riscos ou danificando obras materiais, 
as árvores configuram alamedas impensáveis em grande parte do Brasil, ditando uma cultura unicamente brasiliense. Onde mais se perceberia um playground de figueiras com seus troncos deformados? $\bigcirc$ piso desgastado é um problema menor em face do que se cresceu ali.

\section{CONCLUSÃO}

Esta pesquisa atingiu o objetivo de discutir a vegetação urbana além do que geralmente se discute, apresentando as fitopatologias urbanas e introduzindo uma forma de análise que agrega essa perspectiva, que se mostrou um instrumento capaz de corroborar a correta utilização do verde nas cidades, diagnosticando problemas.

Como descrito, o verde está em quase toda a parte, desde as calçadas até os grandes parques urbanos, e, por isso, é bastante provável que em algum momento aja de forma contrária ao desejo das pessoas. Assim, para implantá-lo e evitar/diminuir degenerações, é necessário compreender suas características e ponderar acerca de várias dimensões que vão muito além da estética.

A ferramenta proposta foca nas problemáticas que se pretendia avaliar, contudo, a análise de fato acompanha arcabouços teórico e prático que não necessariamente estão exemplificados nesta ficha. Para entender a vegetação urbana, seus lados positivos e negativos, e propor algo, deve-se, à semelhança do roteiro proposto por Sandeville Jr. (2004), conhecer uma ampla gama de características da área estudada, isto é, realizar uma análise paisagística que leve em conta os campos cultural, social, ambiental, físico etc. que nortearão a pesquisa.

Será que a problemática ambiental provocada por uma árvore é ruim a ponto de ofuscar suas qualidades estéticas? Será que o problema real é a figueira? Ou a calçada estreita? O que de fato importa nessa "balança" deve ser ponderado.

Embora este trabalho possa parecer, inicialmente, uma análise rápida, um trabalho que refuta o uso da vegetação, os resultados aqui alcançados apontam para a direção contrária, consolidando-se como mais um instrumento de aporte e promoção do verde em nossas cidades. 


\section{REFERÊNCIAS BIBLIOGRÁFICAS}

AMMA. Agência Municipal de Meio Ambiente de Goiânia. Plano Diretor de Arborização de Goiânia Instrução Normativa 030 de 05 de setembro de 2008. Goiânia: AMMA, 2008. Disponível em: <http://www. goiania.go.gov.br/download/amma/relatorio_Plano_Diretor.pdf>. Acesso em: 15 de mar. 2014.

BASSO, Jussara Maria; CORRÊA, Rodrigo Studart. Arborização urbana e qualificação da paisagem. Paisagem e Ambiente: ensaios. São Paulo: FAUUSP, n. 34, 2014, pp. 129-148.

CEMIG. COMPANHIA ENERGÉTICA DE MINAS GERAIS. Manual de arborização. Belo Horizonte: Fundação Biodiversitas, 2011. Disponível em: <http://www.cemig.com.br/sites/imprensa/pt-br/Documents/Manual Arborizacao_Cemig_Biodiversitas.pdf>. Acesso em: 13 de out. 2015.

DOURADO, Guilherme Mazza. Belle Époque dos jardins. São Paulo: SENAC, 2011.

FARAH, Ivete M. C. Árvore e população: as relações que se estabelecem no contexto da cidade. Paisagem e Ambiente: ensaios. São Paulo FAUUSP, v. 1, n. 18, 2004, pp. 99-120.

FEDRIZZI, Beatriz; TOMASINI, Sérgio Luiz V.; CARDOSO, Luciano Moro. A vegetação no pátio escolar: um estudo para as condições das escolas municipais de Porto Alegre - RS. ENCONTRO NACIONAL SOBRE EDIFICAÇÕES E COMUNIDADES SUSTENTÁVEIS - ENECS, 3, 2003, São Carlos. Anais... São Carlos: ENECS, 2003, p.1-12. Disponível em: <http://www.elecs2013.ufpr.br/wp-content/uploads/anais/2003/2003_ artigo_008. pdf $>$. Acesso em: 10 de abr. 2014.

FULGERI, Dalva de Fátima. O conceito de natureza em Rousseau. Paradigmas, ano III, n. 12, jan/fev. 2003. Santos: Centro de Estudos Filosóficos, p. 6.

GONÇALVES, Eduardo Gomes; LORENZI, Harri. Morfologia vegetal. Nova Odessa: Instituto Plantarum, 2011. JACOBS, Janes. Morte e vida das grandes cidades americanas. São Paulo: Martins Fontes, 2010.

KOHLSDORF, Maria Elaine. A apreensão da forma da cidade. Brasília: UnB, 1996.

LAMAS, José M. Ressano Garcia. Morfologia urbana e desenho da cidade. 7 ed. Barcelona: Blume, 2014. LIMA, Roberta Maria Costa e. Avaliação da arborização urbana do Plano Piloto. 2009. 48 f. Dissertação (Mestrado em Ciências Florestais) - Faculdade de Tecnologia, Universidade de Brasília, Brasília, 2009.

LINK, D. Plantas perigosas fazem parte de projetos de arborização e paisagismo. 1998. In: MASCARÓ, Juan Luis; MASCARÓ, Lucia Elvira Alicia Raffo. Vegetação urbana. 2 ed. Porto Alegre: Editora +4, 2015, p. 113.

LYNCH, Kevin. A imagem da cidade. Lisboa: Edições 70, 2005.

MACEDO, Silvio Soares. A vegetação como elemento de projeto. Paisagem e Ambiente: ensaios. São Paulo: FAUUSP, v. 4, 1992, pp. 11-41.

Espaços Livres. Paisagem e Ambiente: ensaios. São Paulo: FAUUSP, v. 7, 1995, pp. 15-56.

MALAMUT, Marcos. Paisagismo: projetando espaços livres. Lauro de Freitas: Livro.com, 2014.

MASCARÓ, J. Luis; MASCARÓ, Lúcia Elvira Alicia Raffo. Vegetação urbana. 4 ed. Porto Alegre: Masquatro, 2015.

MICHAELIS: moderno dicionário da língua portuguesa. São Paulo: Melhoramentos, 1998.

PANERAI, Philippe. Análise urbana. Brasília: UnB, 2006.

RAVEN, Peter H.; EVERT, Ray F.; EICHHORN, Susan E. Biology of plants. New York: Worth Publishers, 1992.

ROMERO, Marta Adriana Bustos. Princípios bioclimáticos para o desenho urbano. Brasília: UnB, 2013.

SALVIATI, Eurico João. Tipos vegetais aplicados ao paisagismo. Paisagem e Ambiente: ensaios. São Paulo: FAUUSP, v. 5, 1993, pp. 9-45.

SMVMA. Secretaria Municipal do Verde e do Meio Ambiente de São Paulo - Manual técnico de arborização urbana. São Paulo: SMVMA, (20-?).

SANDEVILLE JR., Euler. Um roteiro para estudo da paisagem intraurbana. Paisagens em Debate - revista eletrônica da área Paisagem e Ambiente. São Paulo: FAUUSP, n. 2, setembro 2004, pp. 1-6.

SILVA, Caio Frederico e. Caminhos bioclimáticos: desempenho ambiental de vias públicas na cidade de Teresina - PI. 2009. 140 f. Dissertação (Mestrado em Arquitetura e Urbanismo) - Faculdade de Arquitetura e Urbanismo, Universidade de Brasília, Brasília, 2009.

SILVA, Matheus M. A. Verde patológico: a vegetação nos diversos processos de degradação da cidade. 2014. 187 f. Ensaio Teórico (Graduação em Arquitetura e Urbanismo) - Faculdade de Arquitetura e Urbanismo, 
O Nem Sempre Conveniente Verde: Estudos Preliminares de Conceituação e Tipificação de Fitopatologias Urbanas em Espaços Públicos

Universidade de Brasília, Brasília, 2014. Disponível em: <http://issuu.com/maramaldo/docs/>. Acesso em: 11 jun. 2016.

SOUZA, Vinicius Castro; LORENZI, Harri. Botânica sistemática. Nova Odessa: Instituto Plantarum, 2012.

TELES, Delayse Maria. Tratamento paisagístico de espaços livres públicos de Superquadras do Sudoeste: o abandono da concepção modernista. 2005. 84 f. Dissertação (Mestrado em Arquitetura e Urbanismo) Faculdade de Arquitetura e Urbanismo, Universidade de Brasília, Brasília, 2005.

TINOCO, Jorge Eduardo Lucena (Org.). Mapa de danos, recomendações básicas. Olinda: CECl, 2009.

WATERMAN, Tim. Fundamentos do paisagismo. Porto Alegre: Bookman, 2009.

\section{AGRADECIMENTOS}

Agradeço às professoras Juliana Saiter Garrocho e à Giuliana Brito Souza pela coorientação deste trabalho, e à Fundação de Amparo à Pesquisa do Estado de Minas Gerais (Fapemig) pelo apoio técnico e financeiro no início do meu mestrado. 